MedieKultur | Journal of media and communication research | ISSN 1901-9726

Article - Theme section

\title{
Civic engagement through mainstream online newspapers: \\ Possibilities and shortcomings
}

\section{Cecilie Givskov and Hans-Jörg Trenz}

MedieKultur 2014, 56, 44-60

Published by SMID | Society of Media researchers In Denmark | www.smid.dk The online version of this text can be found open access at www.mediekultur.dk

Based on a pilot study of online news making and commenting in Denmark, the article discusses the relationship between online political news making and democracy. Empirical insights on the dynamics of user engagement and debates on mainstream Danish online news platforms are used to delineate the contours of the online public sphere. It is argued that the new digital media should be discussed not only as a new forum for political participation but also in relation to traditional forms of representative democracy. The analysis comprises the technical features and apps that are designed by online news providers in Denmark to facilitate the constitution of new "voice publics". How these voice publics are designed as an element of news making and news distribution and, as such, linked to the old "representative" and "attentive publics" of news consumption is investigated.

\section{Introduction}

The digital age is often portrayed as fundamentally changing our mode of private and public communication; and, as such, it is believed to have a revolutionary effect on democratic politics and the public sphere in general (Wright, 2012, p. 245). By replacing the oneto-many communication of traditional mass media by the many-to-many communication of the new digital and social media, the Web 2.0 and Web 3.0 challenge our established understanding of the relationship between media and democracy (Fuchs, 2008). Many 
scholars discuss the new digital media - primarily, in relation to participatory democracy. The many-to-many communication facilitated by the Web 2.0 and 3.0 is analysed as a new form of political voice and activism. The online communication among users-citizens is expected to open new spaces for civil society, which is approached through horizontal links among like-minded citizens and their new forms of engagement. However, the observation that many-to-many communication has a structural affinity to civil society depends not only on the density of user networks and their communicative exchanges but also on the content of political discussion and the civilising potential of public discourse which needs to be conducive to democratic will formation.

The purpose of this article is to present a pilot study of online news making and commenting in Denmark that can serve as basis for further research on the relationship between online political content as provided by established newspapers and democracy. The (limited) empirical insights into the dynamics of user engagement and debates on mainstream Danish online news platforms will be used to delineate the contours of the online public sphere. As we will argue in the theoretical part, there is a need to discuss the new digital media not only as a new forum for political participation but also in relation to traditional forms of representative democracy. The question of whether social networking sites facilitate new forms of civic engagement should not, therefore, be unrelated to the question of whether they also constitute a broader sphere of public opinion and will formation (Papacharissi, 2002; Bohman, 2004). In the empirical part, we collect evidence of online user engagement in the process of news making and news distribution. Our analysis comprises the technical features and apps that are designed by online news providers in Denmark to facilitate the constitution of new "voice publics". The question is how these voice publics are designed as an element of news making and news distribution and, as such, how they are linked to the old "representative" and "attentive publics" of news consumption.

\section{From social networking to the public sphere: where to look for interlinkages?}

The importance of relating social networking media to the public sphere of mass communication is derived, first of all, from the slow but steady demise of traditional media's capacities to reach out and thereby potentially include the political community at large in processes of democratic will formation. The link between national mass media and the national mass audience has been considerably weakened in Europe as an effect of increasing global media competition, the de-regulation of the media markets, the pluralisation of media products and the corresponding segmentation of audiences. This undermining of the 'masses' as a constituting element of 'media' is happening concurrently with the general transformation of the nation-state's position as the uncontested framework for peoples' lives. Many citizens in Europe move professionally, personally or culturally within a transnational social reality, are affected by new configurations of economic power or 
witness the transfer of political authority to supranational political bodies. The notion of a unitary link of political, social and cultural representation of the political community that was provided by the national public sphere of mass attention is contested, and new media formats are tested out that flexibly respond to the notions of a more active population of consumer citizens. This raises a fundamental question regarding the relationship between civic engagement, the new emerging media environment and the public sphere.

The question what kind of (democratic) public sphere is constituted by the new networking media is discussed in academic literature with different scholars pointing to contradictory evidence. On one hand, there is a general agreement about a decline in peoples' commitment to the established institutions of the democratic nation-state. It is argued that citizens and, in particular, young people are turning away from party politics and that it seems that it is becoming increasingly harder to identify a connection between forms of civic engagement and the spheres of government (Delli Carpini, 2000; Bennett, 2008; Dahlgren, 2011). This has encouraged the diagnosis of "post-democracy" in which media (new and old) no longer serve the purpose of including citizens in arrangements of representative (mass) democracy or provide alternatives for new democratic empowerments (Crouch, 2004).

On the other hand, a "new politics of civil society" is emphasised (Liebert \& Trenz, 2010) through which citizens engage transnationally and mobilise around issues of global concern, especially as young people in post-industrial societies express mistrust and lack of interest in conventional politics (Bennett, 2008; Dahlgren, 2011). Instead of mass consumption, many young people engage through new social media in what can be called social and critical consumption, which occurs as a response to the shift from government to market and the visibility of transnational corporate power (Ward \& de Vreese, 2011). As traditional mass media have primarily served national mass audiences, the role of social networking media is often discussed in connection with these new forms of transnational mobilisation. The emergence of social networking media would, thus, indicate the development of a more participatory and more inclusive transnational public sphere. Direct political movements such as "Occupy Wall Street", the "Arab Spring", "Indignados", the "Alter-globalization Movement" and "Indymedia" (with the slogan "Be the Media") testify to a widespread common perception of a link between social media and civic and political engagement (Bennett, 2008; Dahlgren, 2011).

The question of what qualifies these evolving forms of civic engagement as a public sphere ultimately depends not only on the density of social networking but also on the capabilities of the new online publics to mobilize their voice effectively and reach government (Fraser, 2007; Splichal, 2012). The question of how social networking media empower citizens in a democracy, therefore, cannot be detached from the question of how these social networking media are institutionally embedded in the broader structure of the public sphere. Hence, there is no easy way from civic engagement to civic empowerment. The formation of a popular will that becomes effective and informs government is depen- 
dent on an institutional framework of rights and citizenship (Delli Carpini, 2000; Bohman, 2004; Bennett, 2008; Dahlgren, 2011). With a few exceptions such as the EU citizenship regime (Saward, 2013), such legal and institutional frameworks for democratic enactment are largely absent in the transnational realm. However, while showing signs of weariness at the domestic level, the sovereignty of national governments in the arena of international politics remains untouched, and international organizations (such as the UN, NAFTA, the EU) are deprived of citizen support and engagement.

Transnational political engagement through web-based media platforms might very well establish feelings of civic empowerment. However, if the impact of publics on the course of politics remains limited, the radius of emerging forms of transnational civic engagement will also remain limited (Papacharissi, 2002). The question of whether the Internet can be used as a resource for public sphere building, therefore, is not just technological. The instrumental design of online political communication as a mode of enhancing new forms of democracy is dependent on the kind of institutional environment of rights and citizenship within which these policies are enacted. For this reason, we have restricted our analysis to the established forms of users' engagement with political news through mainstream media sites within the national political space - in this case, in Denmark. This does not exclude the possibility of a transnational dimension of social media political engagement through alternative grassroots or social media sites. However, in the absence of focused attention, these latter sites are less likely to impact democratic will formation and, therefore, are disregarded for the purpose of this analysis.

\section{New forms of civic engagement through online media: possibilities and shortcomings}

The many failures of established democratic institutions to provide a forum for rational discussion of political problems and more inclusive forms of government have resulted in discourses of decline. In relation to the ongoing popularisation and marketization of media and culture, the dominant $20^{\text {th }}$ century models and concepts of democracy - with Jürgen Habermas' theorising as a cornerstone - have also been questioned. Disenchantment with the idea of the masses of national mass media (Lunt \& Livingstone, 2013) has made even more contestable whether the notion of deliberation with its emphasis on the rationality of communication and the equity of participation is applicable or desirable as a normative underpinning of democracy. Within the tradition of radical democracy, it has been emphasized that public discourse is rarely egalitarian and, hence, not the soul of democracy (Schudson, 1997), that democracy among equals has never existed, that democracy must be comprehended as a meeting place for antagonistic interests and that counter publics are formed in opposition to exclusion from hegemonic spheres of debate (Laclau \& Mouffe, 1985; Fraser, 1992). In line with this, the hypothesis of the democratizing potential associated with the digital age and network media is refuted by empirical research showing 
evidence that the social stratification of online political participation follows established patterns of the elite's dominance of political participation. Hence, it does not contribute to more equality (Breindl \& Gustafsson, 2011).

Such theoretical and empirical disputes have invited new understandings of the empirical conditions and normative underpinnings of democracy - hence, also new approaches to the understanding of civic engagement and political participation (Bohman, 2004; Dahlgren, 2006). A tendency in recent media research is to approach civic engagement from daily life and cultural perspectives. This would include, for instance, social network activities, entertainment and fan communities as a form of "pre-political" phenomena (e.g., Benkler, 2006; Jenkins, 2006). In the same vein, the cultural turn in the 1990s towards "recognition" instead of re-distribution - or from old "redistributive" to new "identity politics" (Fraser \& Honneth, 2003) - has been taken up in media studies. Within this strand of thinking, the democratic potentialities of access, deliberation and engagement among audiences have been used to envisage alternative (subaltern) public spheres that valorise "the inclusion of otherwise-marginalised voices and the at-times agonistic expression of difference" (Fraser, 1992). A pivotal question in connection with this is obviously whether we are seeing an emergence of a new participatory culture or whether we are just encouraging people to become better participants in the dominant commercial/capitalist culture that now places emphasis on the expression of difference and cultural origins. In light of this discussion of a public sphere of cultural diversity, it has further been noted that the debate has failed to identify the "public consensus or the political consequence" of this kind of public sphere (Lunt \& Livingstone, 2013). This latter point is particularly relevant with regard to the guiding question of this article on the representative function of the online public sphere and its potential for guiding the process of creating public opinion and will formation that have a potential political impact and address the whole of the political community.

A similar concern is expressed by Peter Dahlgren, who provides a recent example of theorizing the link between the pre-political, the public sphere and levels of government (Dahlgren, 2005; Dahlgren, 2006; Dahlgren, 2011). Dahlgren offers a conceptual basis for opening up the analytical terrain for understandings and explorations of the daily life precursors of a well-functioning public sphere and its relationship to representative democracy and government. For that purpose, Dahlgren distinguishes three analytical dimensions in democracy's communicative spaces, which serve as resources for participation and representation through collective will formation: structures, representation and interaction. The first structural dimension refers to the formal institutional aspects, the political economy and the legal frameworks within which media organisations operate. Within this dimension, questions regarding freedom of speech, access and inclusion/exclusion should be considered. The second representational dimension refers to the output of mass and niche media. Here, the pertinent questions regard fairness, accuracy, completeness, diversity of views, agenda setting, ideological biases and modes of address. The third interactive dimension, according to Dahlgren, becomes decisive for the constitution of new online civic spheres. It 
regards, first, citizen encounters and interpretational use of media output (and, it could be argued, engagement with the formal structures made available) and, second, the communicative interaction between citizens, one-to-one, one-to-many or many-to-many. Interaction emerges from the web of people's everyday life and has its spaces, discursive practices and psycho-cultural aspects. As such, it links with the concept of "civic cultures", which Dahlgren uses to describe the talk and civic engagement of networking citizens in relation to the rationalist concept of deliberation (Dahlgren, 2009, pp. 102-25). The notion of "civic culture" is, thus, meant to provide an "enhanced way" to understand online discussion as an element in the public sphere (Dahlgren, 2009, pp. 149-70). Within the framework of daily life and civil society, Dahlgren suggests that we acknowledge all kinds of talk as precursors of political talk and, moreover, that communicative action is not necessarily rational but makes use of all sorts of aesthetic, rhetorical and narrative strategies. As such, Dahlgren's contributions represent focused attempts to identify the specific meaning, identity and subjectivity-based communicative tenets of opinion and will formation in which the collective "we" unite (Dahlgren, 2006). Dahlgren would, thus, acknowledge that there are various forms through which the emerging, pluralist online civic culture can give expression to a collective "we".

Within the theoretical framework proposed, these expressions of the collective of democracy, however, remain at the level of the self-identification of particular online communities. This leaves open the question of how these new online spaces for civic engagement can also be related to spheres of public opinion and will formation, which encompass the political community at large. We, thus, need to transpose the online communities of civic engagement into the political community of democratic self-government. In order to take this step, we propose in the following to distinguish more systematically between "civic culture" and the "public sphere".

\section{From civic culture to public sphere}

With its emphasis on inclusive participation and talk in issue-related online forums (a kind of online coffee house), the debate on online democracy has neglected one of the central achievements of the evolution of modern public spheres: the claim for all-inclusiveness that could be made credible through the constitution of an anonymous public of focused mass attention. The proliferation of a network of civic engagement by deliberating citizens does not, therefore, stand for the existence of a public sphere. The step from a network to a public sphere requires some form of mediated communication with a potential to generate publicity. That is, the general condition that opinions are not only expressed but also heard by non-present strangers (those who are not reached by the network). Publicity as the "activity of making someone or something communicatively visible" (Splichal, 2012) is a necessary condition for raising the claim of generalized validity beyond the context of social interaction (Bohman, 1999). What seems crucial for these claims of generalized validity (or 
democratic legitimacy) is a "public space" constituted by the media in which online user transactions are reported and discussed from a general point of view. This would require the media to consider the plurality of opinions expressed through networking citizens and to cover, filter and amplify them in a way to bring them to the focused attention of a critical audience. In other words, a shared media infrastructure is needed that would interlink forms of civic engagement and foster rational discourse (or discussion). Hence, the central function of the public sphere is the filtering of plural opinions into a public opinion and, ultimately, into a collective will. Publicity as generated by the public sphere is a constraint in the sense of "imposing visibility" on individual actions and intruding on privacy (ibid.), but it can also become an opportunity in the sense of being part of individual strategies to promote one's privacy, as it is frequently the case in new and social media use. The success of social media networks might as well depend on their promise to facilitate "promotional publicity" (Splichal, 2012. P. 26), i.e., to allow their users to seek to be heard, but they rarely possess the technical-infrastructural requirements for these promotional efforts to be successful.

Therefore, the public sphere is not constituted by the dissemination of private opinions through networks of communication but by focussing public opinion and flows of overlapping publics: "If no overlapping of 'public spheres' would be possible, then no argument would be possible, no dialogue about the norms and forms of publicness, no competition and no chance to ever come to a disagreement, to say nothing about an agreement" (Splichal, 2012). The public sphere, therefore, is not simply a network relying on freedom of expression of private opinions but also on the capability to make one's opinions heard and link them to the flow of public opinion that is constituted by the overlapping of publics. Instead of a network, the public sphere is more accurately described as a "river, with many tributaries flowing into it" (Splichal, 2012, p. 200). This river is the mediator of the evolving online civic cultures and the amplifier of the political talk generated by them. Any discussion of modes of political involvement as facilitated by digital media must, therefore, be informed by an examination of the public sphere and its major representative function of making communicative inputs visible and relevant for all. In the following, we analyse the online expressions of civic cultures and political talk in relation to the kind of visibility generated by them.

\section{An assessment of users' engagement as facilitated by online newspapers}

To test how evolving civic cultures as facilitated by new online media are re-coupled to the general public sphere, we will explore in the following Danish news sites (either professional journalism sites or independent news blogs) as spaces for user activation and civic engagement. Our analysis comprises the technical features and apps that are designed by the news providers to facilitate the constitution of new voice publics and their potential linkages to the old "attentive publics" through the flow of public opinion. 
In order to trace the link between online civic engagement and online visibility, we choose the most visited news sites carrying political debate, i.e., those sites where user engagement is embedded in forms of anonymous mass communication. Our choice to select only the most popular sites is based on the assumption that user interactivity and engagement are more visible and intense where public attention is focused. At the same time, professional online news providers have an interest in making user interactivity economically profitable by engaging users through the various technical features and apps provided by them.

In our analysis, we distinguish available forms of user activation and qualify their role at the level of news making (production and distribution) and at the level of public opinionmaking and identification. First, how has user engagement with news changed mainstream journalism and the journalistic practice of news making and distribution? Does online civic engagement have a potential to contribute to community knowledge (in terms of factual information and news) or is it mainly relevant at the level of knowledge diffusion (through sharing and following news)? Second, how does user engagement become relevant for the expression of public opinion, community values and identities? Here, the restricted scope of this survey does not allow the conduct of a qualitative content analysis of specific debates but rather, in a tentative way, maps the technical features available for collective or individual practices of online commenting.

\section{Findings}

In order to establish the popularity of news sites carrying political content and debate in relation to other forms of Internet usage, we created an Alexa ranking of the 100 most popular web sites in Denmark for the period of June 2013. Against the common assumption of the Internet as a political no man's land where political activists remain isolated from users whose primary interest is to be entertained (Norris \& Curtice, 2006), professional news sites in Denmark rank high among top sites such as Google, Facebook or YouTube. The average Internet user in Denmark regularly visits professional news sites related to print news. In addition, such professional news sites in Denmark continue to maintain their monopoly over independent political blogs, which rank far behind the established news sites in terms of popularity. Only a minority of users visit political blogs and even fewer users actively participate in blogging. ${ }^{2}$ Hence, the five highest-ranked sites carrying political content are related to the five national newspapers in Denmark: 1) ekstrabladet.dk (related to the tabloid paper Ekstra Bladet), 2) bt.dk (related to the tabloid paper BT, 3) politiken.dk, 4) jyllands-posten.dk and 5) b.dk (related to the omnibus papers Politiken, Jyllands-Posten and Berlingske Tidende). Ekstrabladet.dk and bt.dk are ranked as numbers 7 and 13, respectively, of the most visited websites in Denmark. Politiken.dk, jp.dk and b.dk are ranked as numbers 17,28 and 65, respectively. None of these national dailies has offline editions above 100,000. 
Considering these low figures, the web editions help to increase the visibility of these newspapers considerably and to maintain their popularity among Danish readers.

All the newspapers offer technical features for interactivity and generally follow the same model for the management of communication between the paper and its readers. This model includes features for liking and sharing, commenting, polling and tipping. Liking facilities are provided via Facebook by only one of the dailies. The rest of the papers combine sharing and recommending facilities via e-mail, Facebook and Twitter. Sharing and recommending involves posting on the user's Facebook wall. Commenting functions are provided for selected articles - in particular, thematic sections or in letters to the editor. Comments are never direct but moderated (following the rules of the news-site netiquette). Polling is a feature through which users are asked to vote on selected topics or to rank their values and preferences. Tipping is a form of direct interaction between users and journalists, giving users the opportunity to inform the newspaper of events by sending messages or pictures.

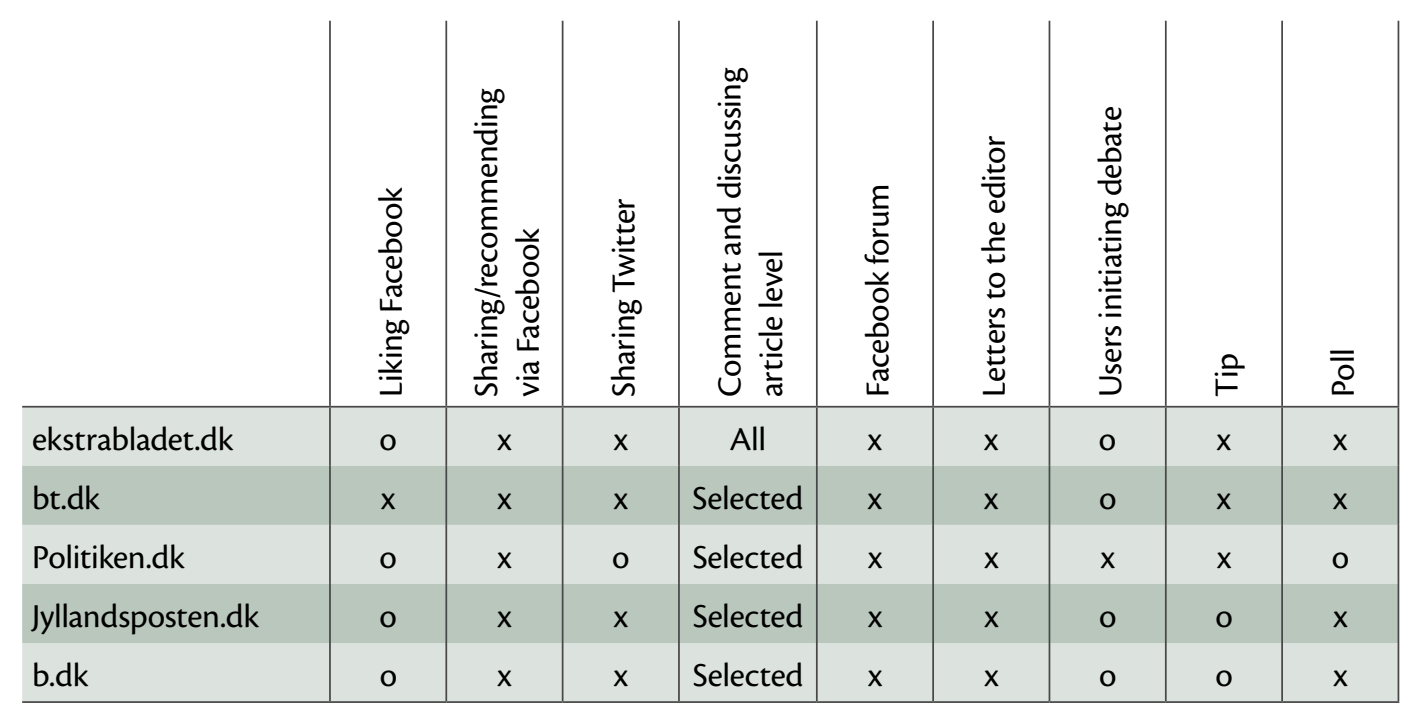

Table 1: Apps for user activation and interaction provided by Denmark's online newspapers

In spite of the general homology among the news sites, the design of the pages testifies to the newspapers' various emphases on inviting participation and strategies employed to comply with and manage the new media environment and the active user. In order to assess how the Danish dailies interpret and negotiate the options available, we take a closer look at the structuring of interactivity and what characterizes the interactive models employed by the different news organizations. We collected the data during the summer of 2013. Beyond the mapping of apps available on each new site we looked into the level of activity on behalf of the news site by counting the number of posts made within 24 hours. With regard to the newspaper's Facebook pages we counted the number of posts made by the newspaper within a week. Moreover, we assessed if and how the newspaper emphasised direct interactions between journalists or editors and users. 
The most popular news site, related to the tabloid Ekstrabladet, has the clearest iconography referring users to Facebook, Twitter and e-mail at the bottom of the page. With respect to news items, interactive options are communicated with large, colourful "buttons". Ekstrabladet.dk's system for interactivity is titled Nationen/The Nation. Users have to become members of the forum although they may remain anonymous to each other when commenting and discussing. Comments and discussion are possible in connection with all published news items. The menu items Politik/Politics and Samfund/Society refer users to subjects related to national and international politics. July 6 2013, 3 stories had been published under the menu item Politics, while 13 stories had been published under Samfund Society. Users commented on these stories, but no moderators or journalists were participating in the comments or discussion related to them. As a more direct form of interaction with journalists, the menu item Nationen/The Nation, the newspaper's online debate forum, offers the option of writing letters to the editor. Letters are submitted to the editor via an email service and remain invisible to other users if not published by the news site. As of July 6, there is no evidence of published letters for the editor in The Nation. At the bottom of the news site, users are directed to Ekstrabladet's Facebook page. Here, the editor posts news items under the name Ekstra Bladet and, sometimes, poses a question in connection to the post and related story. Users cannot post items but may comment and discuss what the editor has selected. Dating a week back from July 6 , two stories from Politics and Society had been published on the site. There was no interactivity related to these stories between the editor and the users.

Ekstrabladet.dk's characteristics largely apply to the other tabloid, BT at bt.dk. However, this newspaper shows less emphasis on interactivity: the iconography is less significant, and fewer options are available for participation. Only selected articles may be commented on and discussed by users. The menu item Politik/Politics refers users to articles on domestic affairs. As of July 9,9 articles had been posted during the past 24 hours of which two were made accessible to user interactivity and one for polling. Dating one week back from July 11, BT published three article from the Politics section on Facebook. There are no specific sections for debate on the bt.dk.

Politiken.dk, the third most popular news site, shows a very discreet approach to invitations to interactivity. Only users familiar with the newspaper's policy on the matter will know where to go on the site, and only users with a public profile are allowed to participate. On the front page, there are no explicit invitations to write letters to the editor or to contribute in other ways (e.g., tipping the newspaper or polling). Neither does the reader find links to Politiken on Facebook and Twitter. With respect to individual articles, users are invited to share them on Facebook and Twitter. At this level, Politiken also provides a function that allows users to tip the newspaper about ongoing events and happenings they think should be included in the coverage. As of July 9, 7 articles had been posted under the menu item Politik/Politics, which covers domestic issues, and 14 under the item International. Instead of creating forums to discuss the articles, Politiken carries a special sec- 
tion for interactivity called Debat/Debate. Here, users are invited to comment and discuss editorials, features, contributions from the newspaper's associated debaters, and selected articles from the Politics and International sections. Politiken in its section Skriv/Write provides a unique feature among the news sites analysed by inviting its users to initiate debate themselves. As of July 9, the most recent posts were written on July 4 and June 22 and 24 . The sub-menu item Leeserbreve/Letters to the editor has four contributions as of July 9 . On Politiken's Facebook site, articles from Politics, International and Debate are rarely posted; and, like the tabloids, editors, moderators or journalists do not visibly participate in the debate in comment sections of the news site itself or on Facebook.

The fourth most popular news site Jyllands-Posten generally has the same structure as Politiken with respect to its sections and the features of interactivity provided. At the bottom of the page, Jyllands-Posten provides links to Facebook and Twitter, and users can share articles via Twitter but not Facebook. There is no invitation to users to tip the newspaper. Under the menu item Debat/Debate, the newspaper posts letters to the editor, but it is not possible for users to comment on these letters. Under the sub-menu item Ordet er dit/The word is yours, users are invited to comment and discuss editorials, features and selected articles. Unlike Politiken, users cannot initiate discussions by themselves. Under the Debate item, the newspaper invites users to take an active part in opinion making initiated by the newspaper's associated bloggers covering different fields. The bloggers are public intellectuals, debaters and politicians. On the newspaper's Facebook site, posts from the Politics and International sections are relatively rare while seven posts from the Samfund section had been made from July 3 to 9 . There was no evidence of interactivity between editors or journalists and the users.

The fifth most popular news site, Berlingske Tidende, follows the same pattern as the other omnibus papers in the structuring of interactivity with its users. However, the newspaper put more emphasis on interactivity with highlighted front-page links to the newspaper's various features for user participation, i.e., blogs, invitations to tip the newspaper, chats with politicians and opinion polls. As with Politiken and Jyllands-Posten, these features figure into a specific debate section from which different services can be accessed. At the bottom of the main page, links to Facebook and Twitter are available. Unlike the two other omnibus papers, Berlingske has a more elaborate Facebook strategy with most of its sections represented on the social network site. Links to these Facebook sections are offered through news site sections, and the paper offers the possibility of sharing articles via Facebook and Twitter. All options are clearly communicated with large buttons. The Politico and Globalt/Global sections carry the newspaper's domestic and international political news and background articles. Here, access is provided to selected articles through Berlingske Forum. Moreover, users are invited to participate in polls on articles containing political viewpoints and positions on concrete political issues. The options are to state whether one is cheering, smiling, bored, sad or angry about a statement or article. The option to comment and discuss the newspaper's contributions from affiliated bloggers is offered under the menu item 
$B$-Tinget/B-Thing. The Debate item offers the option of commenting and discussing associated politicians' contributions. Finally, the Debate section carries the column Groft Sagt/ Roughly Speaking in which associated public debaters make short contributions that are edgy or politically controversial and users are invited to respons. On Politico's and Global's Facebook pages, 14 posts have been made from July 3 to 9 . Posts often include a question to which users may respond, which is an attempt by online editors to steer user debates. Other than that, the newspaper shows the same low degree of interaction between the journalists and their online readers as the other omnibus and tabloid newspapers. ${ }^{3}$

\section{Discussion}

Online print media combine traditional elements of one-to-many news distribution with new features of user activation and interaction. In Denmark, as in other Western countries, mainstream newspapers continue to be the principal sites for the constitution of the national public within its territorial and linguistic confines. Through their online extensions, they principally address the national public while, at the same time, turning into a site for social encounters, thus offering opportunities for a constitution of new online sub-publics. While the former is constituted by attention to the same issues of relevance, the latter allows for the expression of voice and opinion around these same issues.

A high level of control by the newspapers characterises the technical features and apps for interactivity offered by the five most popular online news sites in Denmark. In general, the newspapers we have explored retain control over agenda-setting, select topics for debate and initiate and steer debates by posing explicit questions. Of all five news sites, only Politiken provides a niche for debates that can be initiated by users. In all other instances, the pattern of communication is mono-directional. Explicit invitations by the publisher to debate pre-selected topics are issued on their homepage or through Facebook. Users may post comments and opinions on these pre-selected issues but cannot expect to get responses from editors, moderators or journalists. Moreover, there is no transparency with regard to the newspapers' use of user comments, discussions, sharing or liking in the news production. We might, thus, speak of a "reactive online usage" in which the topics for debate are prescribed by the editors, and user interactions cannot develop spontaneously since individual posts follow the rhythm of the moderators. Another typical example of such "reactive online usage" is the popular polling and online surveys, which often involve thousands of users. While it is clear that such online opinion polls cannot be regarded as scientifically representative, their added value consists primarily in initiating and channelling discussions. However, such online polls and surveys remain reactive and not interactive.

In a similar vein, tipping, which is established by some news sites as a form of direct interaction between users and journalists, falls short of the standards of participatory journalism as laid out, for instance, by Lasica (2003). Tipping by users remains non-transparent as the events and happenings that are tipped are not disclosed to the general public. In all 
these instances, tipping remains restricted to a form of unilateral input by the user, who cannot expect to receive a response from the editors or the journalists.

The widespread practice of liking and sharing a story, in turn, is likely to function as an important feedback mechanism for news production and can be used by the journalists as a valuable indicator of reader preferences and interests. As such, this form of feedback contributes to additional planning, selection and production processes. Our data sources, however, are too incomplete to draw any conclusion on the extent to which liking and sharing also shapes the journalistic content of the news sites included in our survey. When considered as civic engagement, liking and sharing can be classified as a plebiscitarian form of user voice. The conditions under which this feedback contributes to news content remain, however, non-transparent, as journalists rarely disclose their online practices of news making. Liking and sharing, therefore, produce a voice that is potentially heard by journalists and resonates within the user community at large. The conditions for responsiveness and interaction, however, remain limited.

Beyond these general features of online news making, our survey also emphasised persisting differences in online news formats in Denmark. The three more quality-oriented news sites - Politiken, Jyllands-Posten and Berlingske Tidende - are found to be more conservative and less open to interactive formats than Ekstrabladet. Readers interested in quality news will, thus, find it more difficult to enter into debates than readers of tabloids. One possible explanation to be tested by future research is that quality journalists might be particularly attuned to maintaining traditional formats of news making. They claim to serve the truth and to represent objective facts and, therefore, maintain a distance from their readership. They are also found to be absent as participants in user debates and rarely respond to input or critiques posted by users.

Danish news sites also seem to be reluctant to engage with social media. The Facebook and Twitter profiles of all five newspapers are underdeveloped and have not been made into attractive sites for reading news, commenting on it, or engaging in interactions. Newspapers understandably want users to visit their own sites and not to read news on Facebook. They fear that readers might migrate to sites owned by third parties, where they lose ownership and control over their products. Danish news sites are, therefore, reluctant to publish news through social media. They rather try to brand the name of their own product and focus the attention of the audience on their professional news site instead of dispersing it through social media. As shown by the high Alexa ranking of the news sites included in our sample, this business strategy is also successful in substantially attracting user attention.

Citizen engagement with political news is primarily relevant in the form of liking, sharing and "reactive" commenting. The citizen steps forward as an amplifier of pre-fabricated news and as a spontaneous commentator but rarely as a fact provider or as an opinionmaker. User comments remain isolated and detached from opportunities for aggregating opinions, sharing views or expressing community values and identities. Journalists keep full control as gatekeepers of political news and remain the primary framers of news. Faced 
with such readymade news products, citizens are still primarily consumers, and their disposition to challenge values and identities in response to political news is low.

We can, thus, conclude that offline patterns of news production and consumption are largely replicated online with professional journalism and traditional media companies controlling the field. On the positive side of this, we can conclude that the integrative function of newspapers remains intact since online news providers continue to represent the national public and also manage to activate it in new ways. When users of Ekstrabladet, for instance, are requested to sign up as members of a forum as The Nation, they represent the national public and not simply a narrow reader community. It can also be concluded that news reading and commenting on mainstream professional news sites is not marginal but has developed into a substantial part of the online activity of Danish citizens.

On the negative side, the constitution of voice publics as an element of online news making and commenting is found to be restricted in various ways. The voice publics as they become manifest in the comment sections of mainstream news sites are not necessarily more independent than the attentive publics. They rather contribute to the creation of mass attention in the process of commercial news production. This takes place, for instance, through the popular practice of liking and sharing, which can provide important feedback to news production precisely because it measures audience resonance, while the opinion that is liked or shared is still primarily the journalists'. Online news sites, thus, provide the opportunity for the "staging" of user comments in a controlled way, which adds to the content provided by the news editors and journalists put at the disposal of the recipients, who are still primarily conceived as an audience of mass attention.

As such, citizen engagement developing through mainstream online news sites can hardly be said to stand for a new type of civic culture. Online newspapers are still in a stage of pre-interactivity: single user activation instead of users' collective engagement. The features for users' interaction provided by them are primarily meant to make individual users consumers of the news sites and not to engage them collectively. ${ }^{4}$ Yet, this widespread practice of individual citizens engaging in commenting can still be said to be relevant for the democratic process in the sense of contributing to the public sphere of opinion and will formation. News commenting develops into a mass commodity that becomes an integral part of news distribution. Traditional mass media are, thus, found to develop online formats for individual user activation (but not interaction) and, in this way, build on input and throughputs from citizens. The single active user becomes an additional filter and amplifier of news and opinions brought to the attention of a passive mass audience. In this sense, the evolving forms of user activation and engagement with political news are to be understood as an integral part of the public sphere of news consumption and focused attention and not as an alternative public sphere separated from the traditional media sphere. Civic engagement is not a subversive replacement of the structures of mass communication through traditional media but rather a re-organisation of it. 
Through our analysis of the technical features for interactivity in mainstream online newspapers, we can obviously only provide an initial sketchy approximation of online practices of news consumption. Any further assessment of the "quality" of the emerging civic culture of user-citizens engaging with political news would require an in-depth analysis of the sequences of interaction, the content of interventions and the channelling of the opinions expressed. For this purpose, we refer to quantitative and qualitative content analyses (Fortunati, O'Sullivan et al., 2010; Michailidou, de Wilde et al., forthcoming) as well as audience surveys (Norris \& Curtice, 2006; Hindman, 2008), which largely corroborate our findings of the restricted space for user interactions and engagement online.

\section{References}

Benkler, Y. (2006). The Wealth of Networks: How Social Production Transforms Markets and Freedom. New Haven, Conn.: Yale University Press.

Bennett, L.W. (2008). Changing citizenship in the digital age. In L. W. Bennett (Eds.) Civic Life Online: Learning How Digital Media Can Engage Youth (pp. 1-24). Cambridge, MA: MIT Press.

Bohman, J. (1999). Citizenship and norms of publicity: Wide public reason in cosmopolitan societies. Political Theory, 27(2), 176-222.

Bohman, J. (2004). Expanding dialogue: The Internet, the public sphere and prospects for transnational democracy. Sociological Review, 52, Issue Supplement 1, 131-155.

Breindl, Y. \& Gustafsson, N. (2011). Leetocracy: Networked political activism and the continuation of elitism in competitive democracy. In D. Araya, Y. Breindl \& T.J. Houghton, Nexus: New Intersections in Internet Research. New York: Peter Lang.

Crouch, C. (2004). Post-Democracy. Cambridge: Polity Press.

Dahlgren, P. (2005). The Internet, public spheres, and political communication: Dispersion and deliberation. Political Communication, 22, 147-162.

Dahlgren, P. (2006). Doing citizenship: The cultural origins of civic agency in the public sphere. European Journal of Cultural Studies, 9(3), 267-286.

Dahlgren, P. (2011). Young citizens and political participation: Online media and civic cultures. Taiwan Journal of Democracy, 7(2), 11-25.

Delli Carpini, M.X. (2000). Gen.com: Youth, civic engagement, and the new information environment. Political Communication, 17, 341-349.

Fortunati, L., et al. (2010). Interactivity as a metaphor of online news. Javnost-The Public, 17(4), 41-62.

Fraser, N. (1992). Rethinking the public sphere: a contribution to the critique of actually existing democracy. In C.J. Calhoun, Habermas and the Public Sphere (pp. 109-142). Cambridge: MA: MIT Press.

Fraser, N. (2007). Transnationalizing the public sphere: On the legitimacy and efficacy of public opinion in a post-Westphalian world. Theory, Culture \& Society, 24, 7-30.

Fraser, N. \& Honneth, A. (2003). Redistribution or Recognition? A Political-Philosophical Exchange. London: Verso.

Fuchs, C. (2008). Internet and Society: Social Theory in the Information Age. London: Routledge.

Hindman, M. (2008). The Myth of Digital Democracy. Princeton: Princeton University Press.

Jenkins, H. (2006). Fans, Bloggers, and Gamers Exploring Participatory Culture. New York: New York University Press. 
Laclau, E. and C. Mouffe (1985). Hegemony and Socialist Strategy towards a Radical Democratic Politics. London: Verso.

Lasica, J.D. (2003). What is participatory journalism? Online Journalism Review. Retrieved April 16, 2014, from http://www.ojr.org/ojr/workplace/1060217106.php.

Liebert, U. \& Trenz, H.-J. (Eds.) (2010). The New Politics of European Civil Society. London: Routledge.

Lunt, P. \& Livingstone, S. (2013). Media studies' fascination with the concept of the public sphere: critical reflections and emerging debates. Media, Culture \& Society 35(1), 87-96.

Michailidou, A., et al. (forthcoming). The Internet and European Integration. Pro- and anti-EU Debates in Online News Media. Opladen: Barbara Budrich Publisher.

Norris, P. \& Curtice, J. (2006). If you build a political web site, will they come? The Internet and political activism in Britain. International Journal of Electronic Government Research, 2(2), 1-21.

Papacharissi, Z. (2002). The virtual sphere. New Media and Society, 4(1), 9-27.

Saward, M. (2013). The dynamics of European citizenship: Enactment, extension and assertion. Comparative European Politics, 11, 49-69.

Schudson, M. (1997). Why conversations are not the soul of democracy. Critical Studies in Mass Communication, 14(4), 1-13.

Splichal, S. (2012). Transnationalization of the Public Sphere and the Fate of the Public. New York: Hampton Press.

Ward, J. \& de Vreese, C. (2011). Political consumerism, young citizens and the internet. Media, Culture \& Society, 33(3), 399-413.

Wright, S. (2012). Politics as usual? Revolution, normalization and a new agenda for online deliberation. New Media and Society, 14(2): 244-261.

\section{Notes}

1 Alexa.com provides information about web traffic, including top sites for selected periods and countries. Alexa's samplings are inherently biased - underrepresenting, for instance, sites that use https protocol or the Internet usage of data-sensitive users. The top rankings, however, are less affected by this bias.

2 The three most significant Danish political blogs during the past three years are the liberal/conservative "Jarls blog" (jarlcordua.dk), the social democratic "Dansk-politik.dk" and the right wing "Uriasposten" (uriasposten.net). According to Alexa traffic counts, none of them rank among the 500 most visited Danish websites.

3 Research on the various newspaper fora for debate and discussions was undertaken in July. In journalistic terms, the summer months are known as the 'silly season' because most of the staff, the majority of sources and - quite likely - also those interested in contributing to political debate through newspaper websites are on holiday. However, as we have focused on structures for participation and patterns of interactivity, we do not consider the timing of the data collection as compromising the conclusions.

4 Similar findings are reported by Fortunati et al. (2010).

Cecilie Givskov Assistant Professor, PhD. Department of Media, Cognition and Communication University of Copenhagen cecilieg@hum.ku.dk 
Article: Civic engagement through mainstream online newspapers

\section{Hans-Jörg Trenz}

Professor, PhD.

Department of Media, Cognition and Communication

University of Copenhagen

trenz@hum.ku.dk 